\title{
Short communication: Characterization of soluble thiols in bovine milk
}

\author{
G. Niero, M. De Marchi, A. Masi, M. Penasa, ${ }^{1}$ and M. Cassandro \\ Department of Agronomy, Food, Natural resources, Animals and Environment, University of Padova, Viale dell'Università 16, \\ 35020 Legnaro (PD), Italy
}

\begin{abstract}
Antioxidants are molecules essential for the maintenance of cell homeostasis and their intake through the diet has positive effects on human health. Among antioxidants, low-molecular-weight (LMW) thiols represent an important class of compounds. The aim of this study was to identify LMW thiols in bovine milk. A total of 96 individual milk samples from Brown Swiss, HolsteinFriesian, Alpine Grey, and Simmental cattle breeds were collected in 8 herds. The LMW thiols were extracted from the soluble fraction of milk and, following a derivatization protocol, they were separated by reverse phase HPLC and detected fluorimetrically. Six thiol species were detected and 2, glutathione (GSH) and cysteine-glycine (Cys-Gly), were identified and quantified. Regardless of the breed, the average concentration of Cys-Gly in milk was greater than that of GSH. Overall, milk from dual-purpose breeds (Simmental and Alpine Grey) was richer in LMW thiols than milk from dairy cows (Holstein-Friesian and Brown Swiss). Glutathione and Cys-Gly, closely linked metabolically, were strongly correlated. Pearson correlations of Cys-Gly with protein and casein contents were moderately low, and no relationship was found between GSH and milk chemical composition. Future research should focus on the identification of all detected LMW thiol species.
\end{abstract}

Key words: thiol, antioxidant, milk, cattle breed

\section{Short Communication}

Free radicals (FR) are molecules with an unpaired electron in the outer orbit (Gilbert, 2000). For this reason, they are very unstable and reactive, and may have adverse effects on animal and human cells. Free radicals can be divided in 2 major classes. The first includes the reactive oxygen species (ROS) such as superoxide, hydroxyl, peroxyl, alcoxyl and hidroperoxyl radicals, and the second includes the reactive nitrogen species (RNS) such as nitric oxide and nitrogen dioxide

Received April 23, 2015.

Accepted May 29, 2015.

${ }^{1}$ Corresponding author: mauro.penasa@unipd.it radicals (Evans and Halliwell, 2001). These molecules are produced in animal cells as a consequence of space radiations on biological substrates (Kovalev, 1983) or as by-products during the mitochondrial phosphorylative oxidation (Dröge, 2002). Both ROS and RNS play an important role in physiological processes that occur in animal cells, such as signal transduction, gene transcription (Lander, 1997; Zheng and Storz, 2000), pathogens killing, vascular smooth muscle relaxation, leukocyte adhesion, and angiogenesis (Ignarro et al., 1999). However, an excessive production of FR has negative effects on animal cell molecular structures such as lipid peroxidation, oxidative alterations of proteins, and DNA damage (Robbins and Cotran, 2010). These biochemical injuries may lead to clinical diseases such as cancer, atherosclerosis, rheumatoid arthritis, neurodegeneration, and diabetes (Jackson, 1999; Gilbert, 2000).

Antioxidants acting against FR are essential for the maintenance of cell homeostasis. Antioxidants are defined as substances that are able, at relatively low concentration, to compete with other oxidizable substrates, thus preventing their oxidation. This definition includes antioxidant enzymes and molecules acting as antioxidants themselves, such as $\alpha$-tocopherol, $\beta$-carotene, ascorbate, and glutathione (GSH), a tripeptide composed by cysteine, glycine, and glutamate (Halliwell and Gutteridge, 1989). In particular, GSH belongs to the class of low-molecular-weight (LMW) thiols, highly reactive molecules, massively involved in the maintenance of cellular redox homeostasis (Pivato et al., 2014), and in FR scavenge by formation of disulfide bond (Fang et al., 2002). Other LMW thiols, biosynthetically connected with GSH, are cysteine, cysteineglycine (Cys-Gly), cysteamine, and $\gamma$-glutamylcysteine.

The daily intake of these compounds through the diet plays an important role against FR and contributes positively to diseases preventing. The most well known dietary matrices rich in thiols and antioxidants are of vegetable origin (Ames et al., 1993; Halliwell, 1996; Sies, 1997; Beckman and Ames, 1998; Gutteridge and Halliwell, 2000). Few studies have investigated antioxidants and thiols content in animal matrices such as milk and milk whey (Hakkak et al., 2000; Micke et 
al., 2002; Niero et al., 2014). Moreover, most of the literature addressed the problem in a general sense, investigating the total antioxidant capacity of milk (Chen et al., 2003), the antioxidant properties of peptides, caseins, and whey proteins (Chiang and Chang, 2005; Pihlanto, 2006), or the total content of sulfhydryl groups (Cosio et al., 2000). Therefore, the aim of this work was to characterize soluble thiols in milk of dairy and dual-purpose cattle breeds.

Individual milk samples $(\mathrm{n}=96)$ of Brown Swiss (BS), Holstein-Friesian (HF), Simmental (SI), and Alpine Grey (AG) cows from parity 1 to 8 and from 5 to 524 DIM were collected in 8 herds between April and May 2014 by the South Tirol Dairy Association (Bolzano, Italy). The same number of milk samples (n $=24$ ) was available for each breed. Immediately after sampling, milks were added with preservative and transferred at $4^{\circ} \mathrm{C}$ to the laboratory of the South Tirol Dairy Association. Milk chemical composition was determined using a MilkoScan FT6000 (Foss Electric A/S, Hillerød, Denmark) and SCC was assessed by Fossomatic (Foss Electric A/S). Values of SCC were transformed to SCS through the formula $\mathrm{SCS}=3+\log _{2}(\mathrm{SCC} / 100,000)$. An aliquot of each individual sample was transferred to the Department of Agronomy, Food, Natural Resources, Animals and Environment of the University of Padova (Legnaro, Italy), and stored at $-20^{\circ} \mathrm{C}$.

Milk samples were thawed and centrifuged for $10 \mathrm{~min}$ at $16,000 \times g$ at room temperature to promote the separation of fat from the soluble fraction. To ensure protein precipitation, $250 \mu \mathrm{L}$ of the soluble fraction were added with $34 \mu \mathrm{L}$ of $4 \mathrm{M} \mathrm{HCl}$ and centrifuged for $10 \mathrm{~min}$ at $18,000 \times g$ at room temperature. Following this step, a pellet containing high-molecular-weight proteins and a supernatant, composed of LMW proteins and thiols, was obtained. An aliquot of $50 \mu \mathrm{L}$ of supernatant was added with $117 \mu \mathrm{L}$ of $1 M$ borate buffer (pH 10.5), 33 $\mu \mathrm{L}$ of $1 \%$ tributylphosphine, and $33 \mu \mathrm{L}$ of $0.3 \%$ ammonium 7-fluoro-2,1,3-benzoxadiazole-4-sulfonate. The solution obtained was kept in water bath at $60^{\circ} \mathrm{C}$ for $1 \mathrm{~h}$. Samples were cooled in ice for $2 \mathrm{~min}$. The reaction was stopped and the fluorescent products were stabilized by adding $17 \mu \mathrm{L}$ of $4 M \mathrm{HCl}$. Before HPLC analysis, samples were filtered with a 0.22 -nm filter (Masi et al., 2002).

An aliquot of derivatized sample was analyzed in HPLC (Beckman Coulter System Gold 126, Beckman Coulter, Brea, CA), equipped with a reverse phase C18 column (Luna Phenomenex, $150 \times 4.6,3-\mu \mathrm{m}$ particle size; Phenomenex, Torrance, CA). The HPLC analysis was carried out in isocratic conditions $(0.3 \mathrm{~mL} / \mathrm{min})$, with a mobile phase of $75 \mathrm{mM} \mathrm{NH}_{4}$-formiate ( $\mathrm{pH} 2.9$ ) metanol (97:3). Fluorescent compounds were detected with a fluorimetric detector (Jasco 821FP, Jasco, To- kyo, Japan; excitation wavelength $=386 \mathrm{~nm}$, emission wavelength $=516 \mathrm{~nm}$ ). Chromatographic peaks were identified by comparing retention times with 7 different standards. Finally, quantification of each single peak, corresponding to the retention times of standards, was obtained with calibration curves.

The normal distribution of LMW thiols in milk were checked using the Shapiro-Wilk test. Pearson correlations between traits were estimated through the CORR procedure of SAS (SAS Institute Inc., Cary, NC). Sources of variation of LMW thiols concentration in milk were investigated using the GLM procedure of SAS. The model included the fixed effects of breed, herd nested within breed, parity (4 classes: parity 1 , parity 2 , parity 3, and parities 4 to 8 ), DIM (5 classes: 5 to 60 d, 61 to $120 \mathrm{~d}, 121$ to $180 \mathrm{~d}, 181$ to $240 \mathrm{~d}$, and 241 to $524 \mathrm{~d}$ ), and first-order interactions between breed and parity as well as breed and DIM. Significance of breed effect was tested on the herd within breed variance. A multiple comparison of means was performed for the breed effect using the Bonferroni test $(P<0.05)$.

For each milk sample, reverse phase HPLC analysis showed 6 chromatographic peaks, which corresponded to 6 LMW thiols species. Only 2 of them (Cys-Gly and GSH) were identified by comparing the retention time of samples peaks with peaks obtained using internal and external standards (Figure 1). Glutathione is the main cellular LMW thiol and it protects cell components by acting as a redox buffer to quench a variety of reactive chemical species, such as ROS and RNS, or to scavenge or conjugate metals, xenobiotics, and other reactive electrophilic species (Messens et al., 2013). Glutathione is degraded by $\gamma$-glutamyl transferases to yield glutamic acid and Cys-Gly, which is further converted to cysteine and glycine by a dipeptidase. Cysteine, which could not be detected in this study, is indeed generally found at low concentrations because it is known to be either rapidly converted into other compounds or incorporated in proteins.

The mean (SD) concentrations of Cys-Gly and GSH were $0.087(0.068)$ and $0.067(0.064) \mu M$, respectively (Table 1 ), which are comparable with results of Niero et al. (2014) in a study investigating different concentrations of microparticulated whey proteins added during the cheesemaking process on the recovery of LMW thiols in cheese. Means (SD) of fat content, protein content, casein content, and SCS were $3.98(0.61) \%, 3.56$ $(0.46) \%, 2.79(0.37) \%$, and 2.58 (1.84), respectively (Table 1). These values are similar to findings of Penasa et al. (2014), who compared 3 cattle breeds in mixed dairy herds for predicted milk coagulation properties and composition traits. Finally, $\mathrm{pH}$ and urea content averaged 6.66 (SD: 0.06 ) and $22.8 \mathrm{mg} / \mathrm{dL}$ (SD: 7.1), respectively (Table 1 ). Urea concentration reported in 
Table 1. Descriptive statistics of low-molecular-weight thiols and milk quality traits $(\mathrm{n}=96)$

\begin{tabular}{lcccc}
\hline Trait $^{1}$ & Mean & SD & Minimum & Maximum \\
\hline Cys-Gly, $\mu M$ & 0.087 & 0.068 & 0.002 & 0.288 \\
GSH, $\mu M$ & 0.067 & 0.064 & 0.000 & 0.262 \\
Milk yield, kg/milking & 12.4 & 4.1 & 5.0 & 24.0 \\
Fat, \% & 3.98 & 0.61 & 2.51 & 5.53 \\
Protein, $\%$ & 3.56 & 0.46 & 2.61 & 5.50 \\
Casein, \% & 2.79 & 0.37 & 1.98 & 4.38 \\
Lactose, \% & 4.82 & 0.20 & 4.20 & 6.35 \\
SCS & 2.58 & 1.84 & -3.00 & 6.06 \\
pH & 6.66 & 0.06 & 6.48 & 37.7 \\
Urea, mg/dL & 22.8 & 7.1 & 5.9 & \\
\hline
\end{tabular}

${ }^{1}$ Cys-Gly = cysteine-glycine; GSH $=$ glutathione.

our study was slightly greater than findings of other studies (Jonker et al., 2002; Nousiainen et al., 2004).

Cysteine-glycine exhibited moderately low Pearson correlations with protein content $(0.290 ; P<0.01)$, casein content $(0.268 ; P<0.01)$, and urea content $(0.205$; $P<0.05)$, and GSH did not show any significant relationships $(P>0.05)$ with traditional milk components (Table 2). Glutathione and Cys-Gly, which are closely linked metabolically (Wu et al., 2004), were strongly correlated $(0.653 ; P<0.001)$. To our knowledge, no other studies have estimated phenotypic relationships between LMW thiols and traditional milk quality characteristics.

Fixed factors included in the statistical model explained approximately 60 and $40 \%$ of total phenotypic variance of Cys-Gly and GSH, respectively, and breed and herd nested within breed were the most important effects contributing to the variation of LMW thiols (results not shown). The structure of data analyzed in the present work was based on single-breed farms, which means that the herd effect was nested within breed. Despite all farms being located in the same alpine area (Bolzano province) and all milk samples collected within a short period ( $3 \mathrm{wk}$ ), it is likely that

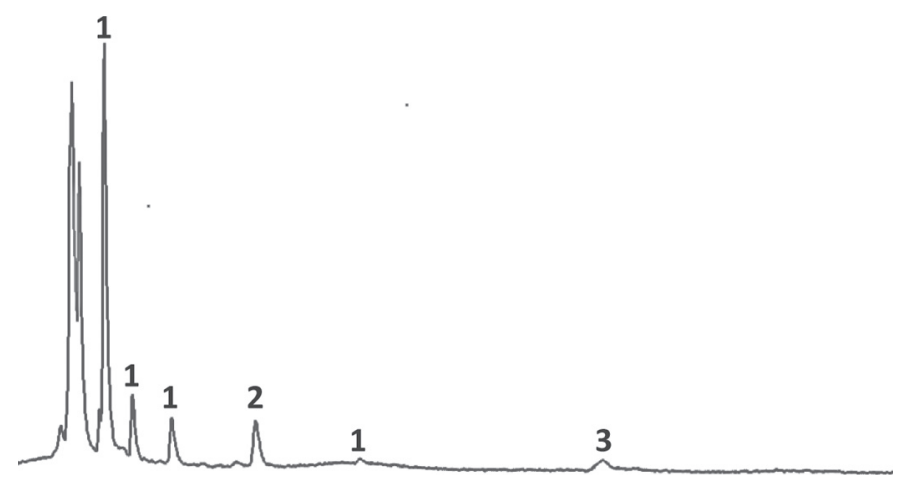

Figure 1. Example of low-molecular-weight thiols chromatogram of milk ( 1 = unidentified chromatographic peaks; 2 = cysteine-glycine; $3=$ glutathione) . managerial and feeding strategies were different among herds and, thus, the breed-estimated effect could also include a part of the rearing conditions effect. Overall, the concentration of Cys-Gly in milk was greater than that of GSH across all cattle breeds. Moreover, LMW thiols were richer in milk from dual-purpose (SI and AG) than dairy (HF and BS) cows (Figure 2). However, breeds did not differ significantly $(P>0.05)$ in terms of GSH concentration in milk, and only BS exhibited a significantly $(P<0.05)$ lower Cys-Gly content than SI and AG cows (Figure 2).

Broadly speaking, the intrinsic reactivity of the nucleophilic sulfhydryl group makes LMW thiol molecules biologically important; as antioxidant molecules, they participate in several reversible redox reactions, they can conjugate and thus deactivate xenobiotics and toxic compounds, and they may also have a technological role with implications for food quality and safety. These aspects may have possible implications on human health. The present study is a first contribution to the characterization of LMW thiols in milk of different cattle breeds. Further studies should be performed to characterize all detected LMW thiols and to quantify total antioxidant milk activity. Moreover, information from the present work can be used to build mid-infrared

Table 2. Pearson correlations between low-molecular-weight thiols and milk quality traits

\begin{tabular}{lcc}
\hline & \multicolumn{2}{c}{ Thiol } \\
\cline { 2 - 3 } Trait $^{1}$ & Cys-Gly & GSH \\
\hline Cys-Gly & & $0.653^{* * *}$ \\
Milk yield & -0.154 & 0.117 \\
Fat & -0.003 & -0.170 \\
Protein & $0.290^{* *}$ & -0.048 \\
Casein & $0.268^{* *}$ & -0.054 \\
Lactose & -0.166 & 0.006 \\
SCS & -0.135 & -0.103 \\
pH & -0.092 & -0.016 \\
Urea & $0.205^{*}$ & 0.176 \\
\hline
\end{tabular}

${ }^{1}$ Cys-Gly = cysteine-glycine; $\mathrm{GSH}=$ glutathione.

${ }^{*} P<0.05,{ }^{* *} P<0.01,{ }^{* * *} P<0.001$. 


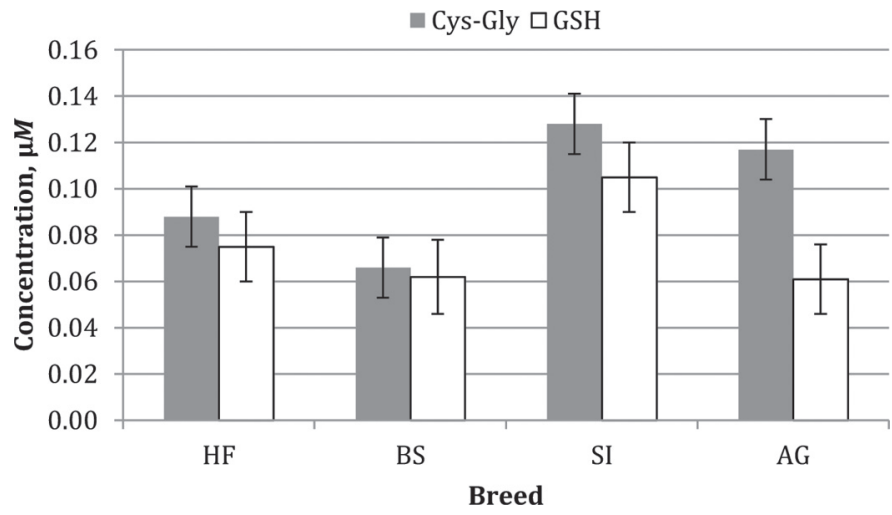

Figure 2. Least squares means (with $\mathrm{SE}$ ) of cysteine-glycine (Cys-Gly) and glutathione (GSH) concentration across breeds $(\mathrm{HF}=$ Holstein-Friesian; BS = Brown Swiss; SI = Simmental; AG = Alpine Grey).

spectroscopy models for the a posteriori prediction of historical spectral data (De Marchi et al., 2014). This would allow collection of LMW thiols at population level to estimate covariance components (if any) and to propose breeding strategies to enhance these traits.

\section{ACKNOWLEDGMENTS}

The authors thank Luis Kerschbaumer and Thomas Kerschbamer (Sennereiverband Südtirol, Bolzano, Italy), Christian Plitzner (Vereinigung der Südtiroler Tierzuchtverbände, Bolzano, Italy), and Martina Isaia (University of Padova) for technical support. M. De Marchi and M. Cassandro coordinated the project; G. Niero designed the dataset and, with A. Masi, performed laboratory analyses to characterize bovine milk soluble thiols; M. Penasa performed statistical analyses; and G. Niero wrote the first draft of the manuscript. All authors contributed to the discussion of the results and reviewed and approved the final version of the work.

\section{REFERENCES}

Ames, B. N., M. K. Shigenaga, and T. M. Hagen. 1993. Oxidants, antioxidants, and the degenerative diseases of aging. Proc. Natl. Acad. Sci. USA 90:7915-7922.

Beckman, K. B., and B. N. Ames. 1998. The free radical theory of aging matures. Physiol. Rev. 78:547-581.

Chen, J., H. Lindmark-Månsson, L. Gorton, and B. Åkesson. 2003. Antioxidant capacity of bovine milk as assayed by spectrophotometric and amperometric methods. Int. Dairy J. 13:927-935.

Chiang, S. H., and C. Y. Chang. 2005. Antioxidant properties of caseins and whey proteins from colostrums. J. Food Drug Anal. 13:57-63.

Cosio, M. S., S. Mannino, and S. Buratti. 2000. Electrochemical sensor detecting free sulfhydryl groups: evaluation of milk heat treatment. J. Dairy Sci. 83:1933-1938.
De Marchi, M., V. Toffanin, M. Cassandro, and M. Penasa. 2014. Invited review: Mid-infrared spectroscopy as phenotyping tool for milk traits. J. Dairy Sci. 97:1171-1186.

Dröge, W. 2002. Free radicals in the physiological control of cell function. Physiol. Rev. 82:47-95.

Evans, P., and B. Halliwell. 2001. Micronutrients: Oxidant/antioxidant status. Br. J. Nutr. 85(Suppl. 2):S67-S74.

Fang, Y. Z., S. Yang, and G. Wu. 2002. Free radicals, antioxidants, and nutrition. Nutrition 18:872-879.

Gilbert, D. L. 2000. Fifty years of radical ideas. Ann. N. Y. Acad. Sci. 899:1-14.

Gutteridge, J. M., and B. Halliwell. 2000. Free radicals and antioxidants in the year 2000. A historical look to the future. Ann. N. Y. Acad. Sci. 899:136-147.

Hakkak, R., S. Korourian, S. R. Shelnutt, S. Lensing, M. J. Ronis, and T. M. Badger. 2000. Diets containing whey proteins or soy protein isolate protect against 7,12-dimethylbenz(a)anthracene-induced mammary tumors in female rats. Cancer Epidemiol. Biomarkers Prev. 9:113-117.

Halliwell, B. 1996. Antioxidants in human health and disease. Annu. Rev. Nutr. 16:33-50.

Halliwell, B., and J. M. C. Gutteridge. 1989. Free Radicals in Biology and Medicine. 2nd ed. Oxford University Press Inc., New York, NY.

Ignarro, L. J., G. Cirino, A. Casini, and C. Napoli. 1999. Nitric oxide as a signaling molecule in the vascular system: An overview. J. Cardiovasc. Pharmacol. 34:879-886.

Jackson, M. J. 1999. An overview of methods for assessment of free radical activity in biology. Proc. Nutr. Soc. 58:1001-1006.

Jonker, J. S., R. A. Kohn, and J. High. 2002. Use of milk urea nitrogen to improve dairy cow diets. J. Dairy Sci. 85:939-946.

Kovalev, E. E. 1983. Radiation protection during space flight. Aviat. Space Environ. Med. 54:S16-S23.

Lander, H. M. 1997. An essential role for free radicals and derived species in signal transduction. FASEB J. 11:118-124.

Masi, A., R. Ghisi, and M. Ferretti. 2002. Measuring low-molecularweight thiols by detecting the fluorescence of their SBD-derivatives: application to studies of diurnal and UV-B induced changes in Zea mays L. J. Plant Physiol. 159:499-507.

Messens, J., N. Rouhier, and J.-F. Collet. 2013. Redox homeostasis. Pages 59-84 in Oxidative Stress and Redox Regulation. U. Jakob and D. Reichmann, ed. Springer, Dordecht, the Netherlands.

Micke, P., K. M. Beeh, and R. Buhl. 2002. Effects of long-term supplementation with whey proteins on plasma glutathione levels of HIV-infected patients. Eur. J. Nutr. 41:12-18.

Niero, G., A. Sturaro, A. R. Trentin, A. Masi, M. De Marchi, and M. Cassandro. 2014. Effect of cheesemaking with microparticulated whey proteins on the concentration of low molecular thiols in cheese. Acta Agrar. Kvár. 18(Suppl. 1):103-108.

Nousiainen, J., K. J. Shingfield, and P. Huhtanen. 2004. Evaluation of milk urea nitrogen as a diagnostic of protein feeding. J. Dairy Sci. $87: 386-398$.

Penasa, M., F. Tiezzi, A. Sturaro, M. Cassandro, and M. De Marchi. 2014. A comparison of the predicted coagulation characteristics and composition of milk from multi-breed herds of Holstein-Friesian, Brown Swiss and Simmental cows. Int. Dairy J. 35:6-10.

Pihlanto, A. 2006. Antioxidative peptides derived from milk proteins. Int. Dairy J. 16:1306-1314.

Pivato, M., M. Fabrega-Prats, and A. Masi. 2014. Low-molecularweight thiols in plants: Functional and analytical implications. Arch. Biochem. Biophys. 560:83-99.

Robbins, S. L., and R. S. Cotran. 2010. Pathologic Basis of Disease. 8th ed. W. B. Saunders Elsevier, Philadelphia, PA.

Sies, H. 1997. Oxidative stress: Oxidants and antioxidants. Exp. Physiol. 82:291-295.

Wu, G., Y. Z. Fang, S. Yang, J. R. Lupton, and N. D. Turner. 2004. Glutathione metabolism and its implications for health. J. Nutr. 134:489-492.

Zheng, M., and G. Storz. 2000. Redox sensing by prokaryotic transcription factors. Biochem. Pharmacol. 59:1-6. 